\title{
The American Pediatric Society
}

\section{Presidential Address to the American Pediatric Society, May 18, 1973}

\author{
Saul Krugman ${ }^{[9]}$
}

Department of Pediatrics, New York University School of Medicine, New York, New York, USA

To be elected President of the American Pediatric Society is a great privilege and a great honor.

The Society, conceived in 1887 and born in 1888 , began its period of growth and development in 1889 . The first scientific meeting was held in the library of the surgeon general's office in Washington and in the newly opened Johns Hopkins Hospital in Baltimore. Our 83rd annual meeting today would have been the 85 th if the Second World War had not caused th cancellation of meetings in 1943 and 1945. Eighty-one rather than 83 members have had the privilege of serving as president, because 2 served twice, Abraham Jacobi as the Ist and 18 th president and L. Emmet Holt, Sr., as the 10 th and 35 th president.

I have chosen as the subject of this presidential address "The American Pediatric Society" because I should like to share with you various historic highlights in the history of this great society, concentrating chiefly on past presidents who as founders had a great influence on its course. The material for this address stems in part from two sources: the American Pediatric Society Semi-Centennial Volume, 1888-1938, prepared by a committee of five members [1], and the History of the American Pediatric Society, 1887-1965, by two former presidents of the society, Harold K. Faber and Rustin McIntosh [5].

The second president, Dr. Job Lewis Smith, has been aptly clescribed by Harold Faber as the "Father of the American Pediatric Society." As Chairman of the Pediatric Section of the Ninth International Medical Congress, he recognized the importance of pediatrics, as well as its neglect by most medical men in the United States. He therefore proposed the organization of a new independent society devoted exclusively to pediatrics. Job Lewis Smith was promptly elected temporary chair- man, the name "American Pediatric Society" was chosen, and notices were sent to a limited number of physicians who were invited to join the society because of their work and interest in promoting a more scientific study of diseases in children. Forty-three physicians who responded to the invitation were subsequently designated as Founders of the American Pediatric Society. It is of interest that more than half of this group were under 40 years of age and only four were over 50 .

I have selected six past presidents for special comment: five were founders of the society in 1888 and the sixth was elected to membership in 1905 .

\section{Abraham Jacobi}

It was Dr. Job Lewis Smith who suggested that Dr. Abraham Jacobi (Fig. 1) be elected as the 1st president of the American Pediatric Society, for at least three reasons: (1) he was without question one of the most distinguished and widely known pediatricians at that time; (2) he was President of the New York Academy of Medicine; and (3) as an officer of the academy he could secure the hall of the New York Academy of Medicine without charge. Dr. Jacobi accepted the nomination to be the first permanent president, and later he did indeed obtain the hall free of charge.

Abraham Jacobi, born in 1830 in Germany of very humble parentage, received his M.D. degree at the University of Bonn in 1851. He was a liberal and an ardent opponent of autocracy and militarism. He participated in the unsuccessful revolution of 1848 in Germany. When he went to Berlin to take his state examinations, he was promptly arrested, charged with high treason, and jailed for 18 months. He was acquitted after a trial, but he was promptly rearrested 


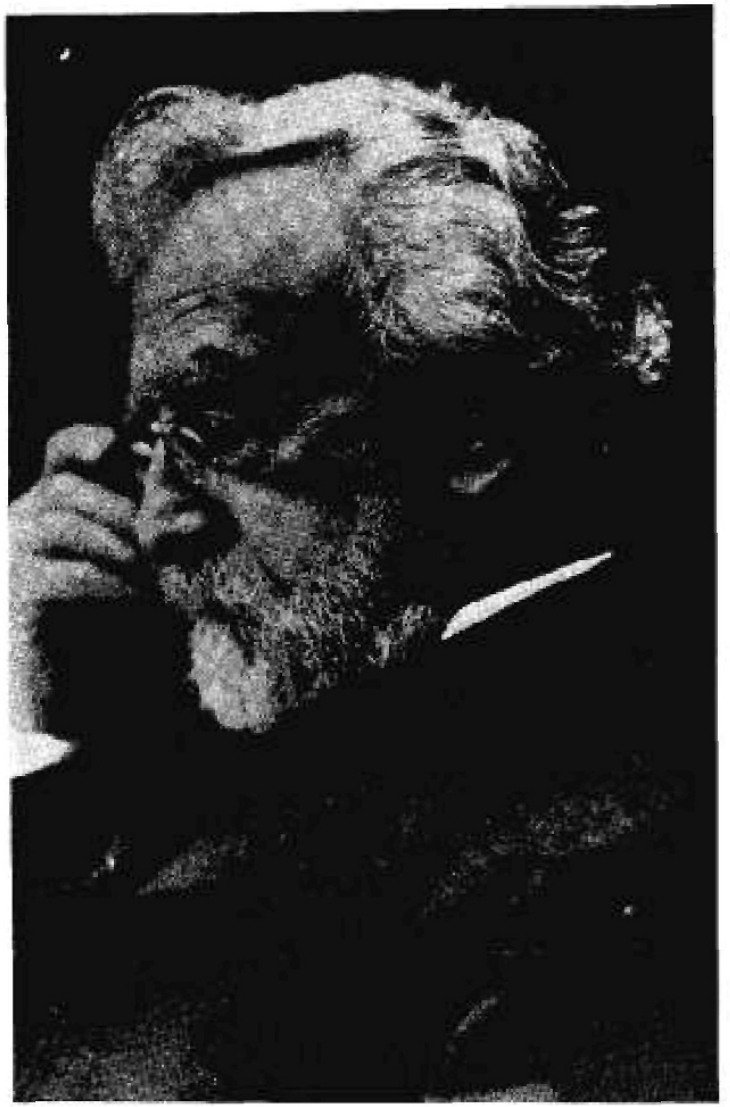

Fig. 1. Abraham Jacobi. Founder and 1st president of the American Pediatric Society.

on another charge and he served another 6 months in prison. At the expiration of this second term, the jailer, who was his friend, arranged to release him during the early hours of the morning and he successfully escaped from Germany before being arrested for a third time on another charge.

Jacobi came to New York in 1853 via Manchester, England, and Boston, Massachusetts. He promptly opened an office for the practice of medicine in the Lower Eastside of Manhattan. His fees were 25 cents for an office visit, 50 cents for house visits, and 5-10 dollars for obstetric cases. He is described as a man of small stature, with explosive energy and an extraordinary organizing ability and drive. He has been called the "Father of Pediatrics" and the founder of the specialty of diseases of children. He was the first professor of pediatrics at Columbia University's College of Physicians and Surgeons in 1870 and he became the first director of the Children's Medical Service at Bellevue Hospital in 1874, serving in this capacity for 31 years. It was Dr. Abt who said of him "throughout his long career, Jacobi consistently manifested those characteristics which distinguished his youth, the love of liberty, abhorrence of oppression, belief in the struggle for human rights, the conviction that all people should be insured protection of inherent privileges and freedom by law, and above all he showed a passionate zeal for righteousness." He was the recipient of nearly every honor that the medical profession can confer on one of its members.

\section{Job Lewis Smith}

Job Lewis Smith (Fig. 2), the 2nd president of the society, presented a striking contrast to Abraham Jacobi. He was a modest, self-effacing, retiring man who made outstanding contributions to the origins of pediatrics. He was considered to be Jacobi's equal in the level of accomplishment and it was believed that "had it not been for Jacobi, Job Lewis Smith would have been the Father of Pediatrics." He was obviously overshadowed by his more dynamic contemporary.

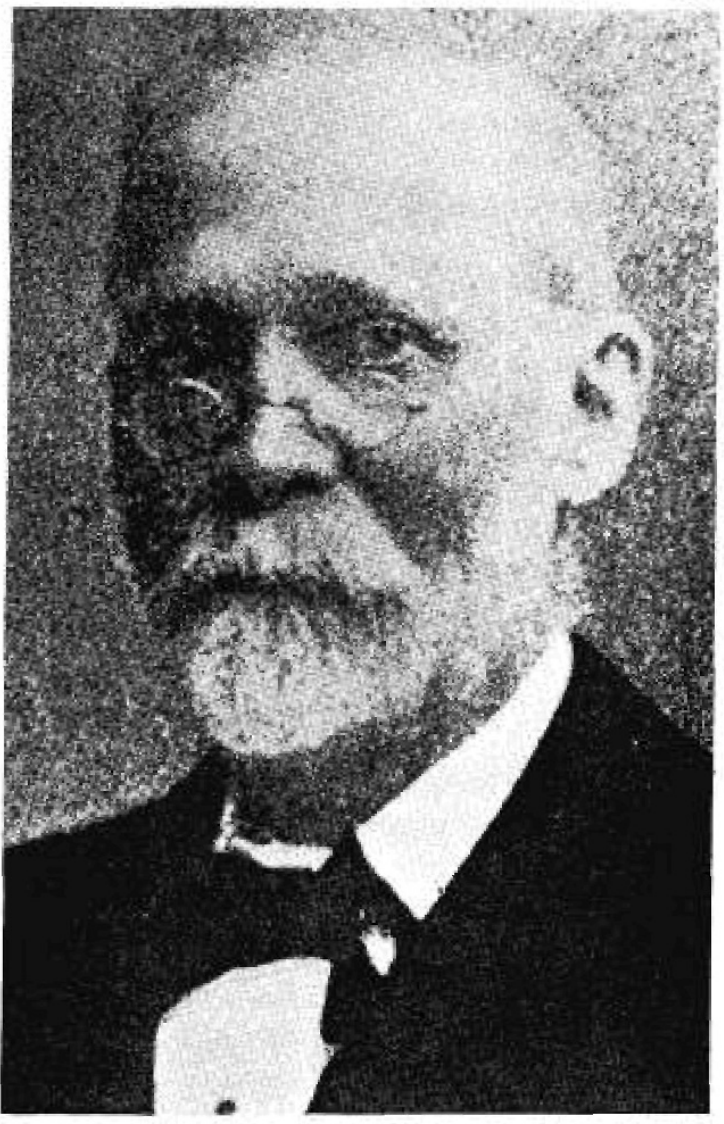

Fig. 2. Job Lewis Smith. Founder and 2nd president of the American Pediatric Society. 
In $1877 \mathrm{Job}$ Lewis Smith was appointed as the first professor of pediatrics of Bellevue Hospital Medical College, an institution which merged with University Medical College in 1897 to form the New York University College of Medicine. I am privileged to be one of Smith's successors in my present capacity as the 8th chairman of this department.

Job Lewis Smith wrote a text on pediatrics; it was the standard text for eight editions until his death in 1897 when it was replaced by Holt's Diseases of Infancy and Childhood. It is of particular interest to me that one of Smith's contributions to medicine was his differentiation of rubella from measles. His findings were described in a report which was published in the October 1874 issue of The Archives of Dermatology.

In his magnificent article entitled "Job Lewis Smith, Forgotten Pioneer" Faber [4] described Smith as one of the two chief pioneers of American pediatrics; his many contributions to the body of medical knowledge were unspectacular but soundly based on direct observation, and on a wide but critically appraised knowledge of the work of others, the earmarks of the scientific mind; his fine character and admirable personal gifts led his associates and followers to call on him repeatedly for a leadership he did not seek; he was an outstanding citizen.

\section{Thomas Morgan Rotch}

Thomas Morgan Rotch (Fig. 3), a founder and the 3rd president of the American Pediatric Society has been called "The Father of Pediatrics in New England." He received his M.D. degree at Harvard University in 1874 and later as Professor of Pediatrics in that institution he established the furst separate department of pediatrics in an American university. $\mathrm{He}$ was a pioneer in the care of premature infants and in the study of physical development. He was a forceful and inspiring teacher, and an author of many important articles, including a textbook entitled Diseases of Children. The senior professorship of pediatrics at Harvard is named for him and this afternoon we shall have the privilege of hearing the present Thomas Morgan Rotch Professor of Pediatrics, Dr. Charles A. Janeway, introduce the 1973 recipient of the John Howland Award.

\section{William Osler}

Our colleagues in internal medicine, and in pediatrics as well, are always surprised when they hear that William Osler (Fig. 4) was a founder and the 4th presi-

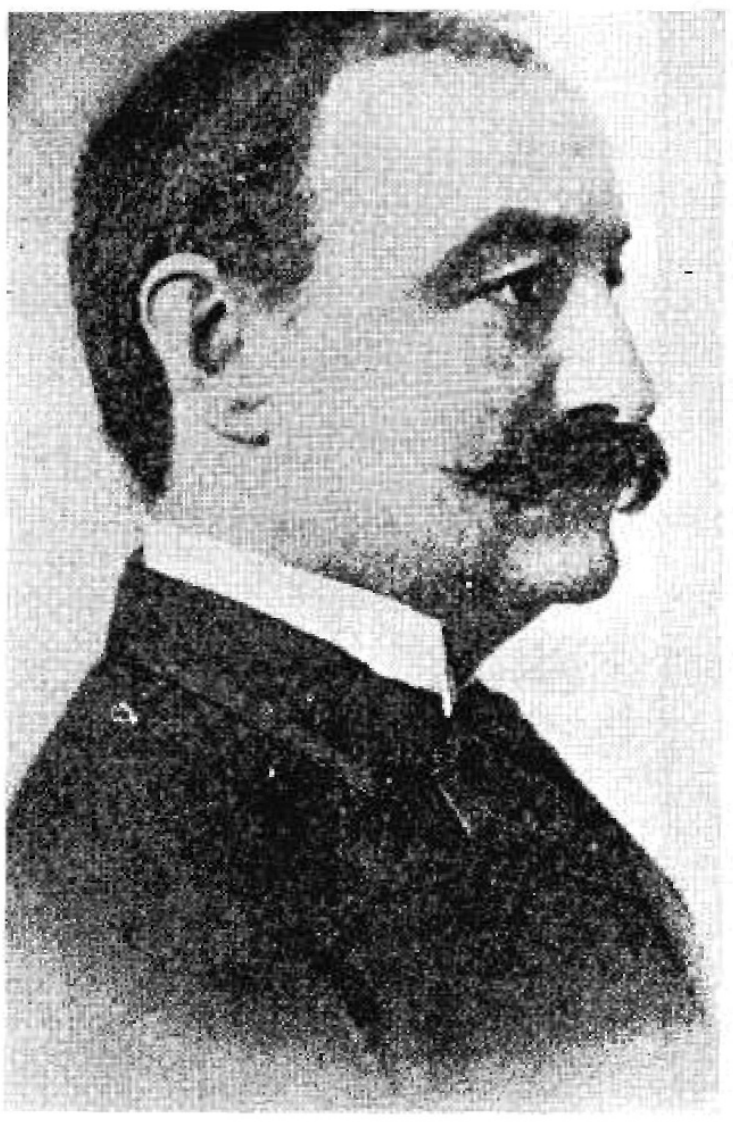

Fig. 3. Thomas Morgan Rotch. Founder and 3rd president of the American Pediatric Society.

dent of the American Pediatric Society. The Life of Sir William Osler has been recorded in a monumental biography by Dr. Harvey Cushing [2]. He dedicated this 2-volume book "to medical students in the hope that something of Osler's spirit may be conveyed to those of a generation that has not known him; and particularly to those in America, lest it be forgotten who it was that made it possible for them to work at the bedside in the wards."

Osler was born in 1849 in Ontario, Canada. It is of interest that this gavel is one of three which was fashioned from the wood of a thorn tree beside the house in which he was born. The second gavel was given to the Association of American Physicians and the third gavel to the Interurban Clinical Club. He received his M.D. degree at McGill University in Montreal in 1872. After studying abroad (London, Berlin, Vienna) for 2 years he returned to McGill where he taught from 1874-1884, when he was called to the University of Pennsylvania to become Professor of Clinical Medicine at the age of 35 . Five years later, in 1889, he accepted 


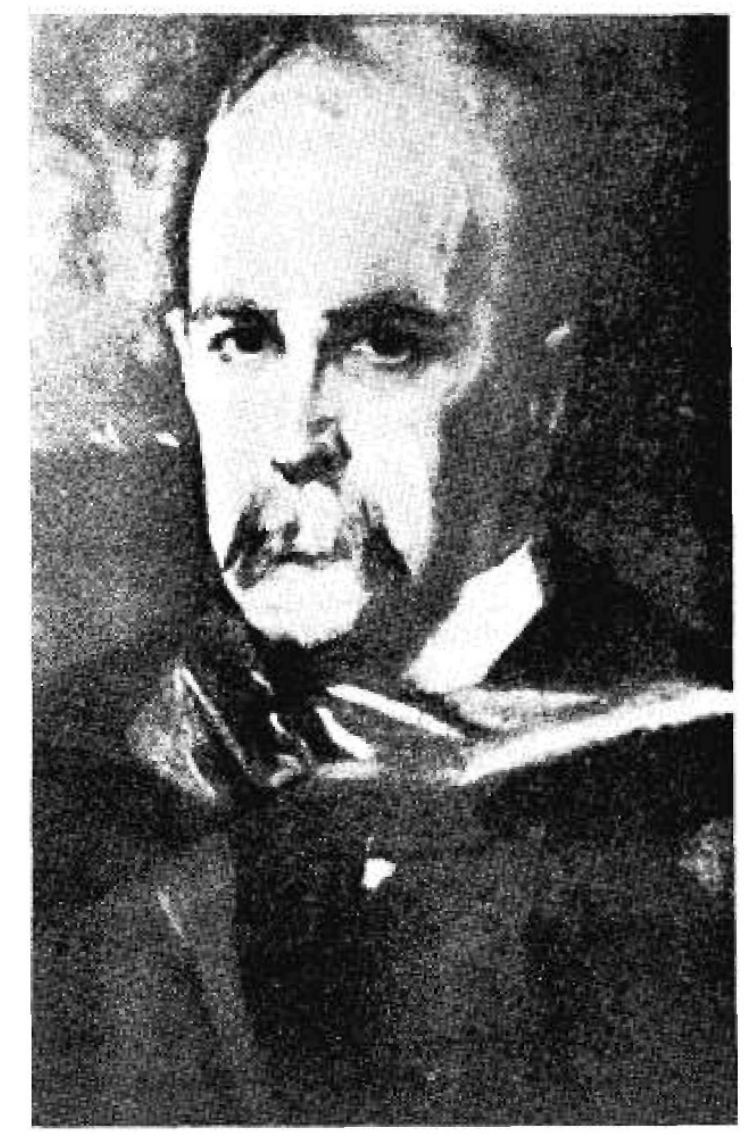

Fig. 4. William Osler. Founder and 4 th president of the American Pediatric Society.

the appointment of Physician-in-Chief of the Johns Hopkins Hospital.

The method employed to recruit Osler as Chairman of the Department of Medicine would be condemned today in this era of participatory democracy when chairmen are selected by search committees with broad representation. And Osler would be considered naive by those recruits of our era who devote many weeks or months of effort in intensive negotiations for space, funds, and other needs of departmental chairmen.

Osler's account of the interview with Dr. John Shaw Billings and his acceptance of the appointment are recorded in his own words: "Early in the spring of 1889 he came to my rooms, Walnut Street, Philadelphia. We had heard a great deal about the Johns Hopkins Hospital, and knowing that he (Billings) was virtually in charge, it at once flashed across my mind that he had come in comnexion with it. Without sitting down he asked me abruptly, "Will you take charge of the Medical Department of the Johns Hopkins Hospital"? Without a moments' hesitation I answered "yes." "See Welch about the details; we are to open very soon. I am very busy today, good morning," and he was off, having been in my room not more than a couple of minutes." Unlike Jacobi, Smith, Rotch and other founders of the American Pediatric Society, Osler's career was devoted almost exclusively to adult medicine.

\section{Emmett Holt, Sr.}

The fifth president and founder who deserves special comment was L. Emmett Holt (Fig. 5), the 10th and 35th president of the American Pediatric Society [3]. He received his M.D. degree at the College of Physicians and Surgeons in 1880. By 1887 his practice was limited exclusively to pediatrics. It is likely that he was the first American to devote his full time to the care of infants and children. In 1901 he succeeded Abraham Jacobi as Professor of Pediatrics at Columbia University.

Emmett Holt lived during the era which saw the awakening of the science of medicine-a period of in-

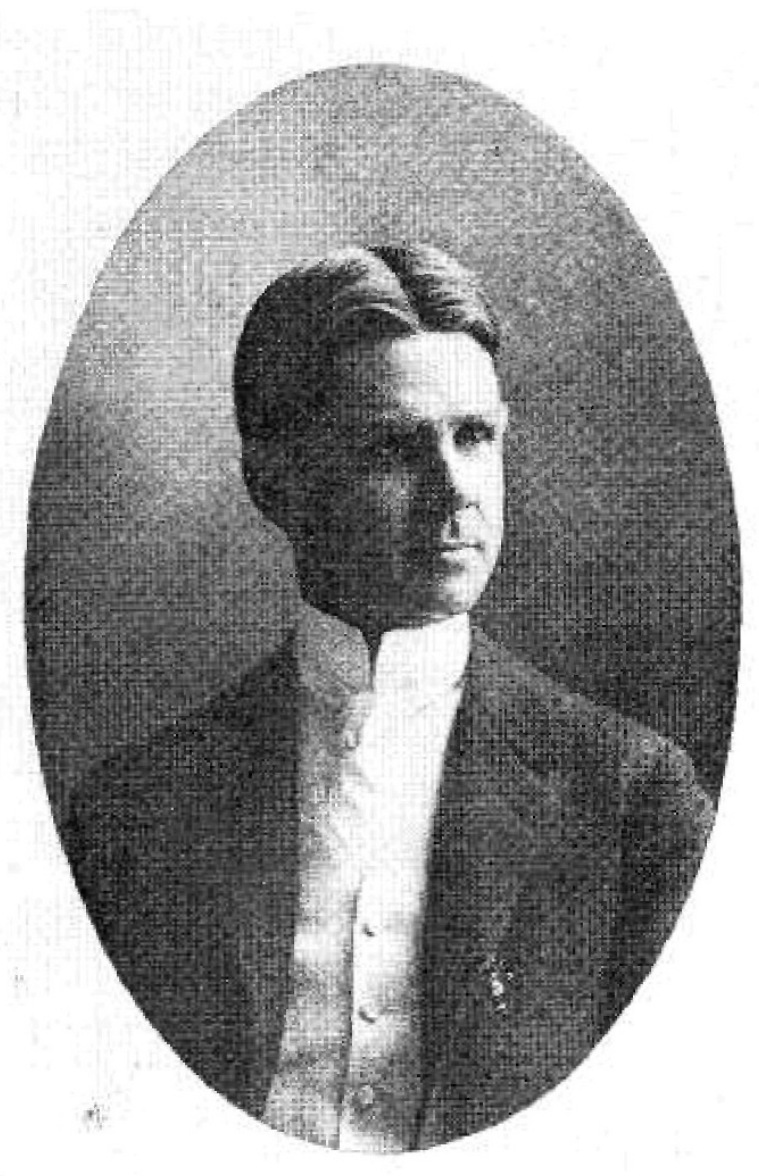

Fig. 5. L. Emmett Holt, Sr. Founder and 5th president of the American Pediatric Society. 
creasing social consciousness which permitted great advances in public health. Early in Dr. Holt's medical career the training of the physician in pediatrics consisted of a few lectures sandwiched into the course on obstetrics. Medicine as a whole was static; it embraced a body of knowledge handed down from generation to generation, knowledge which was neither challenged nor enlarged. The care of the child was not the province of the physician, it was the undisputed domain of the mother and grandmother who passed the tradition on from one generation to the next.

However, at the time of Dr. Holt's death in 1924, information on infant care and hygiene, based on best medical knowledge, was being disseminated to mothers and their children. Medicine had become a dynamic science; disease was being studied by doctors at the bedside, in the clinics, and in laboratories. Diseases of children had assumed a place of major importance and practitioners in this specialty appeared in all parts of country. Full professors of pediatrics were appointed in many medical schools. University departments of

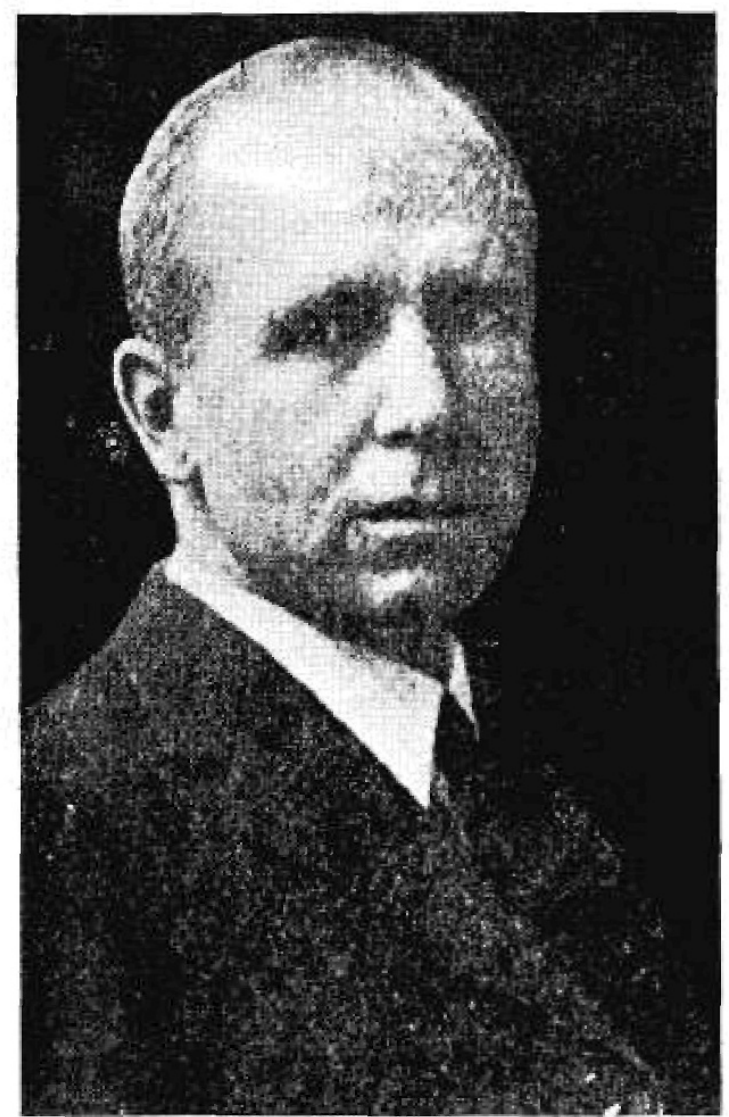

Fig. 6. John Howland. Thirty-third president of the American Pediatric Society. pediatrics and research institutes became a part of the leading medical centers with workers concentrating their efforts on the study of disease in childhood. Pediatric journals and textbooks had been created to diffuse the new knowledge in this branch of medicine. The results were truly dramatic as depicted by the impressive decline in the infant mortality rate. This extraordinary achievement stemmed from the contributions of many individuals. Emmett Holt's outstanding contribution during this era was as an educator. He considered himself to be a "middleman" of science: one who formed the link between the producer, the research worker in the laboratory, and ultimate consumer, who might be the practicing physician, the health worker, or the public. His function was to translate the new knowledge into practical results and to diffuse those results far and wide.

I am especially grateful to Dr. Emmett Holt, Sr., because he had an indirect influence on my career; it was his son, Emmett Holt, Jr., the 71st president of the American Pediatric Society, who accepted me as a member of his department 27 years ago. It is to Emmett Holt, Jr., and to Robert Ward that I shall always be indebted and grateful for encouragement, support, gentle guidance, and help during my early years at New York University Medical Center and Bellevue Hospital.

\section{John Howland}

As Professor of Pediatrics at Columbia University, L. Emmett Holt, Sr., assumed the responsibility of selecting the chiefs of service at Bellevue Hospital. In 1908 he appointed John Howland (Fig. 6) as Director of The Children's Medical Service. John Howland, the 33rd President of the American Pediatric Society, deserves special mention. He was credited with establishing academic pediatrics as we know it today. When he succeeded von Pirquet as Professor of Pediatrics at The Johns Hopkins Hospital he virtually revolutionized student teaching and house staff training by creating the first successful full time university clinical department in any field in this country. He was an outstanding clinician, teacher, investigator, and administrator, an ideal departmental chairman. It was Edwards A. Park who stated "John Howland modernized pediatrics ... he caused it to become a dynamic, rapidly expanding subject. He accomplished this, not by scattering ideas which caused others to act, but by example. The example lay in the development of a model clinic, 
model from the point of view of administration, medical care, teaching, research, spirit."

In 1952 the American Pediatric Society established The John Howland Award and Medal, designating as the basis for the award that part of Article II of the society's constitution which indicates that one objective of this society shall be to honor those who, by their contributions to pediatrics, have aided in its advancement. This afternoon the society will honor its 22nd recipient of The John Howland Award and Medal, Dr. Louis K. Diamond.

The 3rd page of the semicentennial volume of The American Pediatric Society contains an incription with a quote by Dr. S. Weir Mitchell [1]. He described The American Pediatric Society as one of those exclusive organizations whose membership attracted men of training so broad that it insured high quality of work; men whose power to teach was a pledge to that humility which is ever seeking to learn; a society which has no medical politics, and was not embarrassed by useless idlers.

An historic review of the past 82 meetings of The American Pediatric Society indicates very clearly that the society was established for serious purposes with little thought of social functions. However, during the 39 th annual meeting, the society threw off the traditions of its formal dignity and purely professional, scientific demeanor. Who conceived the idea of the riotus revelry of this meeting has never been revealed. The group sailed from Washington for a cruise down the Chesapeake Bay on the S. S. Southland. Everyone was assigned to comfortable quarters, the men with wives off the main cabin, and the bachelors and men released from conjugal obligations to an upper deck, the cocktail row. None of the latter voiced any criticism of this assignment.

After a good dinner, the first scientific session was attended by everyone because there was no other place to go. On the evening of the second day a fancy dress ball was held. Preceding this dancing frolic, there were speeches, short plays, songs, and amusing skits by members. Even the most staid entered into the spirit of the evening with surprising enthusiasm and it was very late before the frivolities were over. Just when the scientific program occurred that day, the transactions fail to state. Since that time, it has never been proposed that such a pleasure excursion be repeated.

In his presidential address in 1924 entitled "American Pediatrics-a Retrospect and a Forecast" Dr. Emmett Holt, Sr., compared the program of 1896 when he had been president before, with that of the present session. Then there had been only one paper portraying the results of a laboratory investigation. Now, in 1924, they filled half the program. Laboratory medicine and preventive medicine were coming into their own. But what of the future? Must the three fields: that of the experimenter, the health expert, and the practitioner of clinical pediatrics, keep on diverging until they became quite separate? Such a segregation seemed almost inevitable, but it would bring a danger which must not be overlooked. The public health doctor must not be cut off from clinical pediatrics. He must be well grounded in it at the start, and only insofar as he could keep abrest of its advances could he properly fulfill his function. The laboratory worker must maintain a contact with the clinic, from which he must draw his problems, and which alone could furnish him with the proper perspective as to their value. The practitioner must keep in touch, on the one hand, with the advances of the laboratory and, on the other, with field of preventive medicine. And the American Pediatric Society, diverse as its interests had become and would continue to be, might still perform a useful function in cementing these individual groups and strengthening each by keeping it in touch with the other.

The scientific program of this 83rd annual meeting of the American Pediatric Society will confirm the accuracy of Dr. Emmett Holt's forecast 49 years ago. Although the interests of our members are indeed diverse, the society in the year 1973 will continue to perform its useful function by providing this common bond for our various specialty groups.

In concluding I should like to leave the past and return to the present, 1973. If Jacobi, Smith, Rotch, Osler, Holt, and Howland were alive today, they would be shocked and dismayed at the incredible decline in support for training, research, and child health services. They would undoubtedly agree with Anne Somers who, in a provocative article in the New England Journal of Medicine, last year stated, "To spend billions of dollars to extend the lifespan of the aged by a few months, sometimes even against their own wishes, and at the same time to neglect the primary causes of ill health and death is both economic and social folly" [6]. The primary causes, I should add, may have their genesis in infancy and childhood.

Instead of the golden era of pediatrics envisioned by the founders of the American Pediatric Society, we find our country plunging into "A Long Day's Journey Into Night." On this last day of my tenure as president of the society I wish to make a plea in behalf of infants and children, a plea to re-establish sane priorities which 
will not condone the financial starvation of programs for child health and human development in order to provied sustenance for programs concerned with cancer, heart disease, and stroke. If this unfortunate trend continues, the progressive decline in infant mortality rate in this country will be reversed and progress in the control of infectious and other diseases of infants and children will cease, thereby creating the paradoxical situation whereby many infants and children will not survive until that age when they would be susceptible cancer, heart disease, and stroke.

During the past 6 months the American Pediatric Society has joined other national medical societies in urging the administration to reverse those decisions which are destined to have a profound and deleterious effect on child health. I have always been an optimist; I feel confident that the impending storm will pass. The sun will rise again to a high noon of progress in child health, providing the climate which will enable the American Pediatric Society to carry out its mission: to bring together men and women for the advancement of the study of children and their diseases, for the prevention of illness and the promotion of health in childhood, for the promotion of pediatric education and research, and to honor those who, by their contributions to pediatrics, have aided in its advancement.

\section{References and Notes}

1. American Pediatric Society Semi-Centennial Volume, 18881938 (privately printed, 1938).

2. Cushing, H.: The Life of William Osler, Ed. 2 (Clarendon Press, Oxford, 1925).

3. Duffus, R. L., And Holt, L. E., JR.: L. Emmett Holt; Pioneer of a Children's Century D. (Appleton-Century Company, New York, London, 1940).

4. Faber, H. K.: Job Lewis Smith, forgotten pioneer. J. Pediat., 63: 794 (1963).

5. Faber, H. K., ANd MCIntosh, R.: History of the American Pediatric Society, 1887-1965 (McGraw-Hill Book Co., New York).

6. Somers, A. R.: Who's in Charge Here?-or Alice Searches for a King in Mediland. New Engl. J. Med., 287: 849 (1972).

7. This address was presented at the $83 \mathrm{rd}$ Annual Meeting of the American Pediatric Society, San Francisco, May 17-19, 1973.

8. Dr. S. Krugman is Professor and Chairman, Department of Pediatrics, New York University School of Medicine, New York, N.Y.

9. Requests for reprints should be addressed to: SAul KRUGMan, M.D., Department of Pediatrics, New York University School of Medicine, New York, N.Y. 10016 (USA).

I0. Received for publication June $7,1973$. 